\title{
Advanced Chronic Kidney Disease is a Strong Predictor of Hypogonadism and is Associated with Decreased Lean Tissue Mass
}

This article was published in the following Dove Press journal: International Journal of Nephrology and Renovascular Disease

\author{
Ryszard Skiba (D) \\ Anna Matyjek ${ }^{2}$ \\ Tomasz Syryło (D) \\ Stanisław Niemczyk $\mathbb{D}^{2}$ \\ Aleksandra Rymarz $\mathbb{D}^{2}$ \\ 'Department of General, Functional and \\ Oncological Urology, Military Institute of \\ Medicine, Warsaw, Poland; ${ }^{2}$ Department \\ of Internal Diseases, Nephrology and \\ Dialysis, Military Institute of Medicine, \\ Warsaw, Poland
}

Purpose: In patients with chronic kidney disease (CKD), hypogonadism is more frequent than in the general population and its prevalence ranges between $40 \%$ and $60 \%$. The aim of the study was to investigate the prevalence of hypogonadism and its association with kidney function, body composition, inflammatory markers and lipid disorders in patients with CKD. Materials and Methods: The study population consisted of 112 men aged $\geq 40$ years in different stages of CKD: 33 participants with eGFR $\geq 60 \mathrm{~mL} / \mathrm{min} / 1.73 \mathrm{~m}^{2}, 27$ men with eGFR $30-59 \mathrm{~mL} / \mathrm{min} / 1.73 \mathrm{~m}^{2}, 17$ predialysis patients with eGFR $<30 \mathrm{~mL} / \mathrm{min} / 1.73 \mathrm{~m}^{2}$, and 35 men on hemodialysis therapy three times a week for more than 3 months (G5D stage). Total testosterone (TT) levels were measured and free testosterone (FT) levels were calculated. Body composition was assessed using bioimpedance spectroscopy (Body Composition Monitor, FMC). Statistical analysis was performed using Statistica version 13.1.

Results: CKD stage was a strong predictor of hypogonadism (providing an information value of 0.83 ). The weight of evidence technique allowed us to differentiate the high-risk group, which was a group of patients with advanced CKD, defined as eGFR $<30 \mathrm{~mL} / \mathrm{min} / 1.73 \mathrm{~m}^{2}$. In this group, the likelihood of hypogonadism was $69.23 \%$. Another significant predictor of hypogonadism was lean tissue index (LTI). TT and FT levels were significantly lower in the advanced CKD group in comparison to the control group, whereas prolactin, luteinizing hormone and Creactive protein levels were significantly higher in the advanced CKD group. The LTI was significantly lower in advanced CKD and was positively correlated with TT and FT.

Conclusion: Decreased eGFR and decreased LTI are predictors of hypogonadism associated with CKD. The study results suggest that hypogonadism screening should be carried out when eGFR deceases below $30 \mathrm{~mL} / \mathrm{min} / 1.73 \mathrm{~m}^{2}$.

Keywords: total testosterone, free testosterone, hypogonadism, chronic kidney disease, lean tissue index

\section{Introduction}

Hypogonadism is diagnosed when both biochemical and clinical conditions defined by the European Association of Urology (EAU) are met. ${ }^{1}$ The biochemical component of this definition is fulfilled when the total testosterone (TT) level decreases below $8 \mathrm{mmol} / \mathrm{L}(2.3 \mathrm{ng} / \mathrm{mL})$ or the TT concentration ranges between 8 and 12 $\mathrm{mmol} / \mathrm{L}(2.3-3.46 \mathrm{ng} / \mathrm{mL})$ with a simultaneous fall in the free testosterone (FT) level to below $220 \mathrm{pmol} / \mathrm{L}(63.45 \mathrm{pg} / \mathrm{mL})$. Among the clinical signs and symptoms of testosterone deficiency, multifactorial dysfunction of homeostasis in the field of body composition, metabolic control over lipids, carbohydrates, sexual and mental health can be enumerated. ${ }^{1}$ In the general population the incidence of
Correspondence: Ryszard Skiba

Department of General, Functional and Oncological Urology Military Institute of Medicine, Szaserów, 128 04-I4I, Warsaw. Poland

Tel +48692916963

$\mathrm{Fax}+48228103174$

Email lynxI I84@gmail.com
International Journal of Nephrology and Renovascular Disease 2020:13 319-327 
hypogonadism is $5 \% .^{2}$ Literature reviews reveal that coincidence of chronic kidney disease (CKD) and hypogonadism varies from $40 \%$ to $60 \%{ }^{3}$ The etiology of low testosterone levels in CKD patients is multifactorial. Dysfunction of the hypothalamus-pituitary-testicular axis is responsible for the higher incidence of hypogonadism in the CKD population. ${ }^{4}$ Successful kidney transplantation restores testis function and ameliorates body composition in most cases. ${ }^{5}$ A study by Fugl-Meyer et al showed that in CKD patients decreased serum testosterone levels, and increased luteinizing hormone (LH) and prolactin levels were present. ${ }^{6}$ In their study, the disorders influenced sexual health quality, although the correlations did not reach statistical significance. ${ }^{6}$ A study by Cobo et al revealed correlations between hypogonadal CKD group and a decrease in lean body mass, low physical activity and poor response to erythropoietin. ${ }^{7}$ A literature review indicates higher mortality rate in patients with stage 3 and 4 CKD with concomitant hypogonadism. ${ }^{8}$

The aim of this study was to investigate the prevalence of hypogonadism and its association with kidney function, body composition, inflammatory markers and lipid disorders in patients with CKD.

\section{Materials and Methods Study Population}

The study population consisted of 112 men aged $\geq 40$ years in different stages of CKD according to the Kidney Disease: Improving Global Outcomes (KDIGO) definition: 33 participants in stages G1 and G2 (eGFR $\geq 60 \mathrm{~mL} / \mathrm{min} /$ $1.73 \mathrm{~m}^{2}$ ), 27 in stage G3 (eGFR $30-59 \mathrm{~mL} / \mathrm{min} / 1.73 \mathrm{~m}^{2}$ ), 17 predialysis patients (G4-G5, eGFR $<30 \mathrm{~mL} / \mathrm{min} / 1.73$ $\mathrm{m}^{2}$ ) and 35 men on hemodialysis therapy three times a week for more than 3 months (G5D stage).

Exclusion criteria were as follows: age $<40$ or $>75$ years, lack of informed consent, post lower extremity amputation state, post cardiac pacemaker implantation state or orthopedic surgery with metal prothesis implantation.

All participants signed their informed consent. The study protocol was accepted by the Military Institute of Medicine Bioethics Committee (approval number 107/ WIM/2018). The study was performed in accordance with the Declaration of Helsinki.

\section{Laboratory Parameters}

Blood samples were taken, after an overnight fast, in hemodialysis patients (group G5D) before the mid-week dialysis session. Plasma was separated within 15 minutes. Plasma for assessing the level of sex hormone binding globulin (SHBG) was frozen at $-80^{\circ} \mathrm{C}$. Hemoglobin and $\mathrm{HbA}_{1 \mathrm{C}}$ were measured from fresh samples or whole blood frozen samples.

In our study, we used the immunochemical method of TT detection. In detail, we used the electrochemiluminescence kit Elecsys Testosterone II (Roche Diagnostics, Switzerland). The serum concentration of FT was calculated with the use of an equation whose formula consists of TT, SHBG, albumin level and constants for albumin and SHBG testosterone binding, available at http://www.issam.ch/freetesto.htm.

A hypogonadic state was defined according to the EAU definition (TT $<8 \mathrm{mmol} / \mathrm{L}$ or TT in the range of $8-12$ $\mathrm{mmol} / \mathrm{L}$ and $\mathrm{FT}<220 \mathrm{pmol} / \mathrm{L}$ ). Beside laboratory parameters, participants were evaluated in a field of clinical signs of hypogonadism. Erectile dysfunction was measured by the 5-item version of the International Index of Erectile Function (IIEF-5) questionnaire. To quantify the severity of hypogonadism, we used the Androgen Deficiency in the Aging Male (ADAM) questionnaire. Moreover, participants underwent a physical examination to look for signs of hypogonadism.

Serum creatinine was measured by the Jaffe method (Gen.2; Roche Diagnostics, Switzerland), serum albumin level by the colorimetric method (Gen.2, Alb 2; Roche Diagnostics, Switzerland) and high-sensitivity C-reactive protein (CRP) by the immunoturbidimetric method (Gen.3, CRPL3; Roche Diagnostics, Switzerland). The following laboratory tests were performed by the electrochemiluminescence method: luteinizing hormone, C-peptide, insulin and prostate-specific antigen (PSA). The kits used were: Elecsys LH II, Elecsys C-Peptide, Elecsys Insulin and Elecsys total PSA, respectively. All kits were produced by Roche Diagnostics (Switzerland). Prealbumin was measured by the immunochemocolorimetric method with the NAS-PRE kit produced by Siemens. Lipid serum concentration was measured by an enzymatic-colorimetric method; and the following kits: Chol2, HDLC3, LDLC3 and TRIGL, were used for total cholesterol, high-density lipoprotein (HDL), lowdensity lipoprotein (LDL) and triglycerides, respectively. Hemoglobin concentration was measured by the SLS method (Sysmex).

\section{Body Composition}

Bioimpedance spectroscopy was performed using the Body Composition Monitor (Fresenius Medical Care). The examination was conducted in supine recumbency 

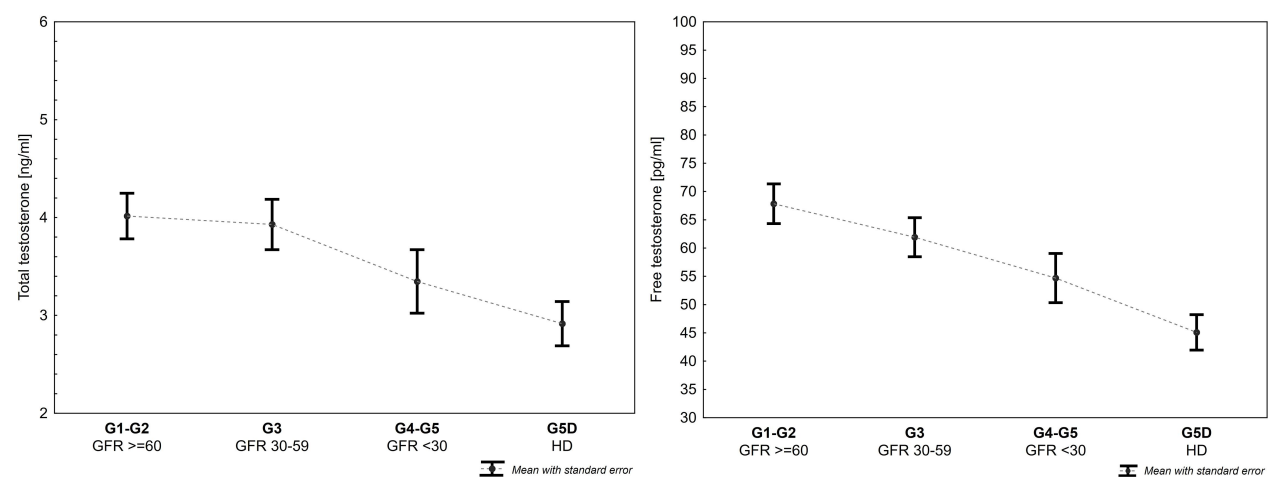

Figure I Comparison of total testosterone (left) and free testosterone (right) concentrations according to CKD stage. Abbreviation: GFR, glomerular filtration rate $\left(\mathrm{mL} / \mathrm{min} / 1.73 \mathrm{~m}^{2}\right)$.

and electrodes were placed in a tetrapolar configuration. In hemodialysis patients, the examination was performed before the dialysis session. In patients with an arteriovenous fistula, electrodes were placed on the upper arm opposite the vascular access.

\section{Statistical Analysis}

Descriptive statistics of continuous variables were presented as mean with standard deviation (SD) for normally distributed data or median with interquartile range (IQR) for non-normal distribution, and as a number with percentage for categorical data. Relationships between continuous variables were estimated with Pearson's or Spearman's correlation coefficient. Comparison of continuous variables was performed using the two-tailed $t$ test or Mann-Whitney test (if two groups were compared) and ANOVA with Tukey's post-hoc test for unequal sample sizes (for comparison of TT and FT in four groups).

The weight of evidence (WoE) technique was used to assess the value of GFR in prediction of hypogonadism. ${ }^{9,10}$ An information value (IV) was used as a measure of its predictive power, with IV $>0.5$ considered as indicative for a strong predictor. Based on the IV, the optimal risk categories were also established: advanced CKD (52 men with GFR $<30 \mathrm{~mL} / \mathrm{min} / 1.73 \mathrm{~m}^{2}$ ) and control group (60 men with GFR $\geq 30 \mathrm{~mL} / \mathrm{min} / 1.73 \mathrm{~m}^{2}$ ). The univariate logistic regression was used to evaluate independent risk factors of hypogonadism in the study population. The results were presented as coefficient with standard error (SE), odds ratio (OR) with $95 \%$ confidence interval $(\mathrm{CI})$ and quality of the univariable model ( $R^{2}$ according to Neglekerke's formula). The significance level for all tests was $p<0.05$. Statistical analysis was performed using Statistica version 13.1.

\section{Results}

The study included 112 men with a median age of 61 years (IQR: 54-67 years, range 40-74 years) in various stages of CKD. There was a significant difference in terms of testosterone levels between men on hemodialysis $(2.91 \pm 1.13$ $\mathrm{pg} / \mathrm{mL}$ ) and patients with eGFR $\geq 60 \mathrm{~mL} / \mathrm{min} / 1.73 \mathrm{~m}^{2}$ as well as in CKD stage G3 $(4.02 \pm 1.72 \mathrm{pg} / \mathrm{mL}$ and $3.93 \pm 1.15$ $\mathrm{pg} / \mathrm{mL}$, respectively). Similar findings were noted in FT concentration (Figure 1).

The likelihood of hypogonadism in the study group was $46.4 \%$. As CKD stage was a strong predictor of hypogonadism (providing an IV of 0.83), the WoE technique was used to categorize different CKD stages according to hypogonadism risk (Figure 2A). Optimal division into risk groups, based on the WoE index, included a high-risk group with eGFR $<30$ $\mathrm{mL} / \mathrm{min} / 1.73 \mathrm{~m}^{2}$ (named the advanced CKD group) and a lower risk group with eGFR $\geq 30 \mathrm{~mL} / \mathrm{min} / 1.73 \mathrm{~m}^{2}$ (named the control group). The likelihood of hypogonadism was $69.23 \%$ in the advanced CKD group and $26.6 \%$ in the control group (Figure 2B).

Moreover, there was a significant difference in the intensity of erectile dysfunction measured by the IIEF- 5 between the advanced CKD group and the control group. The median IIEF-5 score for the advanced CKD group was 15 and for control group was $10(p=0.017)$.

To enhance the accuracy of our analysis, we performed an analysis of hypogonadism subtypes with reference to European Male Ageing Study (EMAS) criteria (Table 1). However, subgroup analysis of biochemical and anthropometric parameters revealed no statistically significant differences between hypogonadism subgroups of our study defined with regard to the EMAS.

With regard to the anthropometric measurements, patients in the advanced CKD group did not differ from 

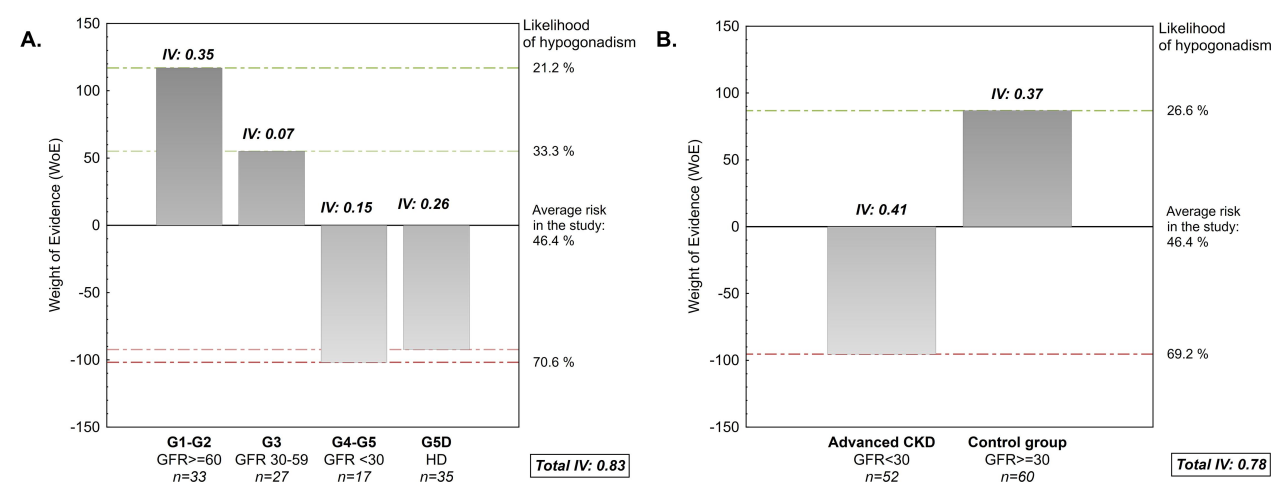

Figure 2 Initial (A) and optimal (B) risk categories of hypogonadism based on CKD stage in the study group (men $\geq 40$ years).

Abbreviations: IV, information value; WOE, weight of evidence (WoE technique).

the control group. Also in terms of age, the groups did not differ significantly. However, body composition evaluation revealed that the advanced CKD group had significantly lower lean tissue mass (LTM), lean tissue index (LTI) and body cell mass (BCM) than the control group. TT serum concentration in the advanced CKD group was also lower than in the control group ( $3.05 \mathrm{vs} 3.98 \mathrm{ng} / \mathrm{mL}, p=0.036$ ), while $\mathrm{LH}(10.1$ vs $6.5 \mathrm{IU} / \mathrm{L}, p<0.0001)$ and prolactin (17.7 vs $9.6 \mathrm{ng} / \mathrm{mL}, p<0.0001)$ concentrations were significantly higher in the advanced CKD group than in the control group. There was no difference in SHBG concentration between the study groups.

Among the biochemical parameters, prealbumin concentration in the advanced CKD group was significantly higher than in the control group ( $36 \mathrm{vs} 29 \mathrm{mg} / \mathrm{dL}, p=0.011$ ). This fact can be explained by different reference ranges for this population associated with decreased prealbumin elimination through the kidneys. Median CRP concentration was significantly higher in the advanced CKD group than in the control group ( $0.4 \mathrm{vs} 0.2 \mathrm{mg} / \mathrm{dL}, p=0.008$ ) which is probably associated with subclinical inflammation associated with CKD. Total cholesterol ( $153 \mathrm{vs} 181 \mathrm{mg} / \mathrm{dL}, p=0.013$ ) and LDL ( 84 vs $107 \mathrm{mg} / \mathrm{dL}, p=0.002)$ median serum concentrations were significantly lower in the advanced CKD than in the control group. This observation can be explained by the higher statin usage in the advanced CKD than in the control group $(65.7 \%$ vs $30.8 \%$, respectively). There was no difference in HDL concentration between the examined groups. Overhydration was significantly higher in the advanced CKD group than in the control group ( 1.9 vs $0.5, p<0.0001)$. General characteristics of the groups are presented in Table 1.

Calculation of the relationship between the studied parameters showed a significant negative correlation between TT and serum creatinine $(r=-0.25, p=0.007)$ concentrations in the whole study population. A significant positive correlation was observed between eGFR and TT concentrations $(r=0.25, p=0.007)$. We observed negative correlations between TT and CRP both in the whole study group $(r=-0.23, p=0.013)$ and in the advanced CKD group $(r=-0.30, p=-0.029)$. Among body composition parameters, LTI correlated positively with TT concentrations in the whole study population $(r=0.22, p=0.27)$. There were significant negative correlations between TT and fat tissue index (FTI) both in the whole study population and in the control group $(r=-0.46, p=0.001)$ as well as fat percentage, also in the whole group and in the control group ( $r=-0.47, p=0.000$ ). All significant correlations between TT, FT concentrations and selected variables are presented in supplementary Table 1.

FT concentrations inversely correlated with serum creatinine in the whole study population $(r=-041$, $p=0.0001)$. We observed a positive correlation between FT and LDL $(r=0.2, p=0.046)$. There were negative correlations between FT and CRP in the whole study population $(r=-0.3, p=0.002)$ as well as in the control group $(r=-0.33$, $p=0.016$ ). Significant negative correlations between FT and SHBG were observed in the advanced CKD group $(r=-0.44, p=0.001)$ and in the whole study population ( $r=$ $-0.23, p=0.019)$. Negative correlations were also observed between FT and both prolactin $(r=-0.25, p=0.01)$ and LH $(r=-0.31, p=0.001)$ concentrations in the whole study population. Body composition parameters represented by LTI correlated positively with FT in the whole study population $(r=0.23, p=0.24)$, whereas FTI $(r=-0.35$, $p=0.015)$ and fat percentage $(r=-0.33, p=0.023)$ negatively correlated with FT in the control group.

In reference to our results, we decided to establish risk factors of hypogonadism in the CKD population. 
Table I Characteristics of the Advanced CKD and the Control Group

\begin{tabular}{|c|c|c|c|}
\hline Parameter & $\begin{array}{l}\text { Advanced CKD Group } \\
(n=52)\end{array}$ & $\begin{array}{l}\text { Control Group } \\
(n=60)\end{array}$ & $p$-Value \\
\hline \multicolumn{4}{|l|}{ Demographic data } \\
\hline Age [years] & $61[53-67]$ & $61[55-67]$ & $0.464 *$ \\
\hline \multicolumn{4}{|l|}{ Diabetes } \\
\hline Yes & 25 & 18 & $0.078^{\wedge}$ \\
\hline No & 25 & 37 & \\
\hline Data missing & 2 & 5 & \\
\hline \multicolumn{4}{|l|}{ Anthropometric measurements } \\
\hline Height $[\mathrm{cm}]$ & $174 \pm 5$ & $174 \pm 6$ & 0.793 \\
\hline Weight $[\mathrm{kg}]$ & $90 \pm 17$ & $92 \pm 16$ & 0.434 \\
\hline BMI $\left[\mathrm{kg} / \mathrm{m}^{2}\right]$ & $29.5 \pm 5.5$ & $30.4 \pm 4.8$ & 0.392 \\
\hline \multicolumn{4}{|l|}{ Hormonal status } \\
\hline \multicolumn{4}{|l|}{ Hypogonadism } \\
\hline With low LH (CH) & 0 & I (6.25\%) & 0.031 \\
\hline With normal LH (iPH) & $12(33.3 \%)$ & $10(62.5 \%)$ & \\
\hline With high LH (PH) & $24(66.7 \%)$ & $5(31.25 \%)$ & \\
\hline \multicolumn{4}{|l|}{ No hypogonadism } \\
\hline With normal LH (EuG) & $3(18.75 \%)$ & $33(75 \%)$ & $<0.0001$ \\
\hline With high LH (cPH) & $13(81.25 \%)$ & II (25\%) & \\
\hline \multicolumn{4}{|l|}{ Erectile dysfunction } \\
\hline IIEF-5 score & $10(3-16)$ & $15(10-20)$ & $0.017 *$ \\
\hline \multicolumn{4}{|l|}{ Biochemical measurements } \\
\hline Serum creatinine $[\mathrm{mg} / \mathrm{dL}]$ & $6.5[4.3-9.2]$ & I.2 [0.9-0.7] & $<0.0001 *$ \\
\hline eGFR $\left[\mathrm{mL} / \mathrm{min} / \mathrm{l} .73 \mathrm{~m}^{2}\right]$ & $9.6[6.1-15.5]$ & $66.7[45.1-91.8]$ & $<0.000 I^{*}$ \\
\hline Serum albumin $[g / d L]$ & $4.2 \pm 0.5$ & $4.4 \pm 0.4$ & 0.017 \\
\hline Prealbumin [mg/dL] & 36 [29-39] & 29 [23-35] & $0.011 *$ \\
\hline Total cholesterol $[\mathrm{mg} / \mathrm{dL}]$ & $153[124-189]$ & $18 \mid$ [145-209] & $0.013 *$ \\
\hline HDL & $42[35-46]$ & $43[40-52.5]$ & $0.068^{*}$ \\
\hline LDL & $84[6|-| \mid 3]$ & $107[86.5-142]$ & $0.002 *$ \\
\hline Triglycerides [mg/dL] & $17 \mid$ [111-199] & $14 \mid$ [104-199] & $0.397^{*}$ \\
\hline C-reactive protein $[\mathrm{mg} / \mathrm{dL}]$ & $0.4[0.2-0.7]$ & $0.2[0.1-0.4]$ & $0.008 *$ \\
\hline SHBG [nmol/L] & $44.8[31.1-58]$ & 44 [32.9-54.7] & $0.76^{*}$ \\
\hline \multicolumn{4}{|l|}{ Hormonal measurements } \\
\hline Total testosterone $[\mathrm{ng} / \mathrm{mL}]$ & $3.05 \pm 1.15$ & $3.98 \pm 1.48$ & $0.036 \#$ \\
\hline Free testosterone $[\mathrm{pg} / \mathrm{mL}]$ & $48.4 \pm 18.5$ & $64.8 \pm 17.9$ & $<0.0001$ \\
\hline Prolactin [ng/mL] & $17.7[13.6-26.2]$ & $9.6[8.2-12.2]$ & $<0.0001 *$ \\
\hline LH [IU/L] & $10.1[8.5-15.5]$ & $6.5[4.5-8.9]$ & $<0.0001 *$ \\
\hline \multicolumn{4}{|l|}{ Bioimpedance spectroscopy } \\
\hline LTM [kg] & $43 \pm 9.3$ & $48 \pm 9.8$ & 0.009 \\
\hline LTM\% [\%] & $49.1 \pm 12.4$ & $53.4 \pm 12.7$ & 0.086 \\
\hline LTI $\left[\mathrm{kg} / \mathrm{m}^{2}\right]$ & $14.1 \pm 2.9$ & $15.7 \pm 2.6$ & 0.004 \\
\hline LTI_dif from ref $\left[\mathrm{kg} / \mathrm{m}^{2}\right]$ & $-0.3 \pm 2.6$ & $1.7 \pm 2.3$ & $<0.0001$ \\
\hline $\mathrm{BCM}[\mathrm{kg}]$ & $23.8 \pm 6.5$ & $27.4 \pm 6.6$ & 0.006 \\
\hline ATM [kg] & $44 \pm 16.9$ & $42.8 \pm 16.5$ & 0.719 \\
\hline Fat $[\mathrm{kg}]$ & $32.3 \pm 12.4$ & $31.4 \pm 12.1$ & 0.717 \\
\hline Fat\% [\%] & $34.9 \pm 9.4$ & $33.4 \pm 9.1$ & 0.406 \\
\hline
\end{tabular}


Table I (Continued).

\begin{tabular}{|l|l|l|l|}
\hline Parameter & $\begin{array}{l}\text { Advanced CKD Group } \\
(\mathbf{n = 5 2 )}\end{array}$ & $\begin{array}{l}\text { Control Group } \\
(\mathbf{n}=\mathbf{6 0})\end{array}$ & $\mathbf{p}$-Value \\
\hline FTI $\left[\mathrm{kg} / \mathrm{m}^{2}\right]$ & $14.5 \pm 5.6$ & $14.1 \pm 5.4$ & 0.725 \\
FTI_dif from ref $\left[\mathrm{kg} / \mathrm{m}^{2}\right]$ & $9.2 \pm 5.6$ & $8.2 \pm 5.3$ & 0.325 \\
TBW [L] & $42.5 \pm 6.3$ & $44 \pm 6.1$ & 0.228 \\
ECW [L] & $20.8 \pm 3.2$ & $20.3 \pm 2.8$ & 0.372 \\
ICW [L] & $21.7 \pm 3.8$ & $23.7 \pm 3.8$ & $\mathbf{0 . 0 0 9}$ \\
OH [L] & $1.9[0.6-3.3]$ & $0.5[-0.7$ to I] & $<0.000$ I* \\
\hline
\end{tabular}

Notes: * $p$-value of Mann-Whitney test; ^ $p$-value of Fisher's exact test; \#p-value of unequal variance $t$-test; $p$-values in bold are statistically significant.

Abbreviations: ATM, adipose tissue mass; BCM, body cell mass; BMI, body mass index; $\mathrm{CH}$, central hypogonadism; $\mathrm{cPH}$, compensated primary hypogonadism; dif from ref, difference from reference; ECW, extracellular water; eGFR, estimated glomerular filtration rate; EuG, eugonadal; FTI, fat tissue index; HDL, high-density lipoprotein; ICW, intracellular water; IIEF-5, International Index of Erectile Function; iPH, primary hypogonadism with inadequate LH response; LDL, low-density lipoprotein; LH, luteinizing hormone; LTI, lean tissue index; LTM, lean tissue mass; OH, overhydration; PH, primary hypogonadism; TBW, total body water.

Therefore, the model of single-factor logistic regression in prediction of hypogonadism was established. In this model, common risk factors for hypogonadism were examined in our population. The strongest single risk factor for hypogonadism was advancement of kidney failure, with the cut-off point at the level of GFR $<30 \mathrm{~mL} /$ $\min / 1.73 \mathrm{~m}^{2}$. In patients with GRF below $30 \mathrm{~mL} / \mathrm{min} / 1.73$ $\mathrm{m}^{2}$, the risk of hypogonadism was increased by 6.19 times. In our study, based mainly on a CKD population, it was a stronger risk factor for hypogonadism than age (OR 1.01) or body mass index (OR 1.04) (Table 2).

\section{Discussion}

The incidence of hypogonadism in the general population is $2.1-5.7 \% .^{11}$ In the CKD population the occurrence of low testosterone concentrations is significantly higher and varies from $26 \%$ to $66 \%$ depending on the degree of kidney function impairment. ${ }^{3}$ In our study, low testosterone levels fulfilling hypogonadism criteria were observed in $46.4 \%$ of the study population. This disorder was significantly more frequent in patients with advanced CKD and reached the level of $69.2 \%$ in patients with eGFR lower than $30 \mathrm{~mL} / \mathrm{min} / 1.73 \mathrm{~m}^{2}$. Such a high prevalence of hypogonadism in CKD men is associated with many factors causing disturbances in the hormonal hypothalamic-pituitary-testicular axis. In $\mathrm{CKD}$, the most important factors that inhibit testosterone production are hyperprolactinemia, subclinical inflammation, obesity and concomitant treatment of other diseases. $^{12}$

In the present study, mean TT and FT concentrations decreased gradually in more advanced CKD stages to

Table 2 Univariate Logistic Regression Models Evaluating Independent Markers of Hypogonadism in the Study Population

\begin{tabular}{|c|c|c|c|c|c|}
\hline Variable & Level of Effect & Coefficient \pm SE & OR $(95 \% \mathrm{Cl})$ & $p$-Value & $R^{2}$ \\
\hline eGFR & $\begin{array}{l}\text { GFR } \geq 30 \\
\text { GFR }<30\end{array}$ & $\begin{array}{l}\text { Ref } \\
1.82 \pm 0.42\end{array}$ & $6.19(2.72-14.06)$ & $\begin{array}{l}- \\
<0.0001\end{array}$ & 0.23 \\
\hline Diabetes & $\begin{array}{l}\text { No } \\
\text { Yes }\end{array}$ & $\begin{array}{l}\text { Ref } \\
3.44 \pm 0.06\end{array}$ & $0.47(0.21-1.04)$ & $\begin{array}{l}- \\
0.064\end{array}$ & 0.04 \\
\hline Age & & $0.01 \pm 0.02$ & $1.01(0.96-1.05)$ & 0.788 & 0 \\
\hline SA & & $-0.29 \pm 0.36$ & $0.75(0.37-1.5 \mathrm{I})$ & 0.421 & 0.01 \\
\hline SHBG & & $-0.02 \pm 0.009$ & $0.98(0.96-0.997)$ & 0.024 & 0.09 \\
\hline BMI & & $0.04 \pm 0.04$ & $1.04(0.97-1.12)$ & 0.287 & 0.01 \\
\hline LTI & & $-0.21 \pm 0.08$ & $0.81(0.69-0.94)$ & 0.006 & 0.11 \\
\hline LTI dif from ref & & $-0.31 \pm 0.09$ & $0.74(0.61-0.88)$ & 0.001 & 0.16 \\
\hline LTM & & $-0.05 \pm 0.02$ & $0.95(0.91-0.99)$ & 0.018 & 0.08 \\
\hline LTM\% & & $-0.05 \pm 0.02$ & $0.95(0.92-0.98)$ & 0.004 & 0.12 \\
\hline
\end{tabular}

Note: $p$-Values in bold are statistically significant.

Abbreviations: BMI, body mass index; CKD, chronic kidney disease; eGFR, estimated glomerular filtration rate; LTI, lean tissue index; LTM, lean tissue mass; SA, serum albumin; SHBG, sex hormone binding globulin.; diffrom ref, difference from reference. 
reach the lowest concentration in men on hemodialysis. Similar results were reported by Yilmaz et al, who observed that low FT and TT concentrations became more frequent in advanced stages of $\mathrm{CKD} .{ }^{13}$ In this study, the average TT serum concentration was 10.9 $\mathrm{nmol} / \mathrm{L}(3.14 \mathrm{ng} / \mathrm{mL})$ when GFR was below $30 \mathrm{~mL} / \mathrm{min} /$ $1.73 \mathrm{~m}^{2}$. This level of TT concentration meets the biochemical criteria for hypogonadism defined by the EAU. This observation was also confirmed by the results of our study, which showed a gradual decrease in TT and FT concentrations along with progression of kidney failure. The mean TT concentration in men with GFR lower than $30 \mathrm{~mL} / \mathrm{min} / 1.73 \mathrm{~m}^{2}$ was $3.05 \mathrm{ng} / \mathrm{mL}$ (Table 1 ). The most important result of the present study is the quantification of the level of kidney failure below which the probability of hypogonadism dramatically increases (Table 2, Figure 2). In our study, in men with GFR lower than $30 \mathrm{~mL} / \mathrm{min} /$ $1.73 \mathrm{~m}^{2}$ the probability of hypogonadism was $69.2 \%$ and the risk of being hypogonadal was 6.19 times greater than in men with GFR $\geq 30 \mathrm{~mL} / \mathrm{min} / 1.73 \mathrm{~m}^{2}$.

Hormonal disorders leading to decreased testosterone concentration in CKD patients include increased prolactin concentrations and changed pituitary LH secretion. The baseline LH concentrations are high, pulsatile secretion is still present but the amplitude is diminished. ${ }^{14}$ Hyperprolactinemia in the CKD population is caused by both decreased clearance of prolactin and its increased production. Furthermore, hyperprolactinemia inhibits gonadotropin releasing hormone $(\mathrm{GnRH})$ production. ${ }^{15}$ The study by Hylander and Lehtihet revealed a systematic increase in serum prolactin concentration with CKD progression. ${ }^{16}$ Our study confirms this observation. In the advanced CKD group, serum prolactin and LH concentrations were significantly higher in comparison to the control group (Table 1). Negative correlations between FT and prolactin as well as LH levels also support this trend.

CKD is recognized as a low-grade inflammatory state and increased levels of proinflammatory cytokines in CKD patients are widely described in the literature. ${ }^{17}$ Subclinical inflammation in the general population is responsible for hypothalamus suppression and as a consequence plays an important role in the pathogenesis of hypogonadism. ${ }^{18}$ The inflammatory state is one of the factors responsible for decreased testosterone concentrations in the CKD population. ${ }^{3}$ In our study, both FT and TT negatively correlated with CRP concentrations and the mean CRP concentration was significantly higher in the advanced CKD group. Similar results were presented by
Cobo et al, who described higher concentrations of inflammatory markers (CRP) in a population of hypogonadal men with CKD. ${ }^{19}$

One of the effects of testosterone action on body homeostasis is the influence on lipid parameters. In the general population, testosterone deficiency is associated with increased cholesterol and triglyceride concentrations, as well as with a decreased level of HDL. ${ }^{20}$ In the study by Gungor et al, the authors observed associations between low testosterone and high values of lipid parameters. ${ }^{21}$ On the other hand, Hylander and Lehtihet observed negative correlations between both FT and TT and triglyceride serum concentrations. ${ }^{16}$ In our study, we did not observe correlations between either TT or FT concentrations and lipid parameters. Moreover, the advanced CKD group had lower total cholesterol and LDL concentrations, which could be associated with frequent statin usage and/or the possibility of coexistent protein-energy wasting (PEW) in the advanced CKD group. In our study, significantly lower serum albumin concentration and lower LTI were observed in the advanced CKD group in comparison to the control group. Decreases in these two parameters are included in the PEW diagnostic criteria. ${ }^{22}$

The main component of the LTI is muscle mass. The influence of testosterone concentration on muscle formation is well known in the general population and in CKD patients. ${ }^{23}$ Loss of muscle mass and strength is associated with frailty, and patients with CKD suffer from this disorder more frequently than the general population. ${ }^{24}$ In the present study, patients with advanced kidney failure (eGFR $<30 \mathrm{~mL} /$ $\mathrm{min} / 1.73 \mathrm{~m}^{2}$ ) had significantly lower LTI in comparison to patients with eGFR $\geq 30 \mathrm{~mL} / \mathrm{min} / 1.73 \mathrm{~m}^{2}$. Moreover, decline of muscle mass is associated with increased risks of major adverse cardiovascular events, kidney disease progression and increased mortality. ${ }^{25,26}$ Among substances which directly influence the molecular mechanisms leading to muscle wasting are protein-bound uremic toxins such as indoxyl sulfate, indole-containing compounds, parathyroid hormone, glucocorticoids and angiotensin $\mathrm{II} .{ }^{27} \mathrm{In}$ the uremic state, reactive oxygen species (ROS) and inflammatory cytokines are present in muscles and enhance myostatin expression, which induces muscle degradation through the ubiquitin-proteasome system. ${ }^{27}$ In our study, positive correlations between the LTI and TT as well as FT concentrations in the whole study population were observed. The lack of significant correlations between testosterone concentrations and lean tissue in advanced CKD may be associated with the small sample size and/or the abnormalities of body 
composition present in CKD. Cigarrán et al revealed that TT deficiency is associated with a loss of fat-free mass and correlates negatively with fat mass. ${ }^{28}$ Another study assessing FT levels and LTI in men on hemodialysis also confirms these results in a CKD population. ${ }^{29}$ On the other hand, the study by Amiri et al revealed that a hypogonadal state increased the hazard ratio of developing CKD in males by 1.26 in comparison to eugonadal men. ${ }^{30}$

Aside from the influence of testosterone levels on muscle mass, this anabolic hormone can also affect fat tissue. Some researchers noted an inverse correlation between testosterone concentrations and fat mass in individuals with normal kidney function as well as in CKD patients. ${ }^{31}$ In our study, TT levels significantly and negatively correlated with fat parameters in the whole study group as well as in the control group (individuals with eGFR $\geq 30 \mathrm{~mL} / \mathrm{min} / 1.73 \mathrm{~m}^{2}$ ). Mechanisms which may explain this phenomenon can be associated with the fact that fat tissue is a source of aromatase and high amounts of leptin. Enzyme aromatase converts testosterone to estradiol, which inhibits LH synthesis. Likewise, hyperleptinemia inhibits gonadotropins in the pituitary gland and this leads to a decrease in testosterone levels.

Taking into account the influence of testosterone on body composition, the replacement therapy of this hormone can be beneficial. In an RCT, Supasyndh et al observed an increase in free-fat mass and a decrease in fat mass after 24 weeks of oxymetholone supplementation in hemodialysis patients. ${ }^{32}$ However, the exact indications and safety of testosterone therapy remain to be evaluated.

\section{Conclusion}

The results of our study showed that the degree of kidney insufficiency expressed by CKD stages and the decrease in muscle mass expressed by the lean tissue index were predictors of hypogonadism in CKD patients. CKD patients should be screened for hypogonadism when GFR decreases to $30 \mathrm{~mL} / \mathrm{min} / 1.73 \mathrm{~m}^{2}$. This screening is intended for the most vulnerable subgroup of the CKD population and may result in beneficial treatment. Our observation needs to be evaluated in further studies.

\section{Disclosure}

The authors report no conflicts of interest in this work.

\section{References}

1. EAU Guidelines on Male Hypogonadism. Edn Presented at the EAU Annual Congress Barcelona 2019. EAU Guidelines Office:Arnhem, The Nederlands.
2. Hall SA, Esche GR, Araujo AB, et al. Correlates of low testosterone and symptomatic androgen deficiency in a population-based sample. $J$ Clin Endocrinol Metab. 2008;93(10):3870-3877. doi:10.1210/ jc.2008-0021.

3. Carrero JJ, Stenvinkel P. The vulnerable man: impact of testosterone deficiency on the uraemic phenotype. Nephrol Dialysis Transplant. 2012;27(11):4030-4041. doi:10.1093/ndt/gfs383.

4. Thirumavalavan N, Wilken NA, Ramasamy R. Hypogonadism and renal failure: an update. Indian $J$ Urol. 2015;31(2):89-93. doi:10. 4103/0970-1591.154297

5. Reinhardt W, Kübber H, Dolff S, Benson S, Führer D, Tan S. Rapid recovery of hypogonadism in male patients with end stage renal disease after renal transplantation. Endocrine. 2018;60(1):159-166. doi:doi:10.1007/s12020-018-1543-2

6. Fugl-Meyer KS, Nilsson M, Hylander B, Lehtihet M. Sexual function and testosterone level in men with conservatively treated chronic kidney disease. Am J Mens Health. 2017;11(4):1069-1076. doi:10.11 77/1557988317703207

7. Cobo G, Gallar P, Di Gioia C, et al. Hypogonadism associated with muscle atrophy, physical inactivity and ESA hyporesponsiveness in men undergoing haemodialysis. Nefrologia. 2017;37(1):54-60. doi:10.1016/j.nefro.2016.04.009

8. Khurana KK, Navaneethan SD, Arrigain S, Schold JD, Nally JV Jr, Shoskes DA. Serum testosterone levels and mortality in men with CKD stages 3-4. Am J Kidney Dis. 2014;64(3):367-374. doi:10.1053/ j.ajkd.2014.03.010

9. Zdravevski E, Lameski P, Kulakov A, Weight of evidence as a tool for attribute transformation in the preprocessing stage of supervised learning algorithms. The 2011 International Joint Conference on Neural Networks, San Jose, CA; 2011: 181-188. doi:10.1109/ IJCNN.2011.6033219.

10. Listen data. Weight Of Evidence (WOE) and Information Value (IV) explained Available from: https://www.listendata.com/2015/03/weightof-evidence-woe-and-information.html. Accessed July 22, 2020.

11. Wu FC, Tajar A, Pye SR, et al. Hypothalamic-pituitary-testicular axis disruptions in older men are differentially linked to age and modifiable risk factors: the European Male Aging Study. J Clin Endocrinol Metab. 2008;93(7):2737-2745. doi:10.1210/jc.2007-1972

12. Carrero JJ, Kyriazis J, Sonmez A, et al. Prolactin levels, endothelial dysfunction, and the risk of cardiovascular events and mortality in patients with CKD. Clin J Am Soc Nephrol. 2012;7(2):207-215. doi:10.2215/CJN.06840711

13. Yilmaz MI, Sonmez A, Qureshi AR, et al. Endogenous testosterone, endothelial dysfunction, and cardiovascular events in men with nondialysis chronic kidney disease. Clin J Am Soc Nephrol. 2011;6 (7):1617-1625. doi:10.2215/CJN.10681210

14. Edey MM. Male sexual dysfunction and chronic kidney disease. Front Med (Lausanne). 2017;4:32. doi:10.3389/fmed.2017.00032

15. Dousdampanis P, Trigka K, Fourtounas C. Hypomagnesemia, chronic kidney disease and cardiovascular mortality: pronounced association but unproven causation. Hemodial Int. 2014;18(4):730-739. doi:10.1111/hdi.12159

16. Hylander B, Lehtihet $\mathrm{M}$. Testosterone and gonadotropins but not SHBG vary with CKD stages in young and middle aged men. Basic Clin Androl. 2015;25:9. doi:10.1186/s12610-015-0027-y

17. Rymarz A, Bartoszewicz Z, Szamotulska K, Niemczyk S. The associations between body cell mass and nutritional and inflammatory markers in patients with chronic kidney disease and in subjects without kidney disease. J Ren Nutr. 2016;26(2):87-92. doi:10.1053/j. jrn.2015.09.005

18. Grossmann M, Ng Tang Fui M, Cheung AS. Late-onset hypogonadism: metabolic impact. Andrology. 2019. doi:10.1111/andr.12705

19. Cobo G, Cordeiro AC, Amparo FC, Amodeo C, Lindholm B, Carrero JJ. Visceral adipose tissue and leptin hyperproduction are associated with hypogonadism in men with chronic kidney disease. J Ren Nutr. 2017;27(4):243-248. doi:10.1053/j.jrn.2017.01.023 
20. Kelly DM, Jones TH. Testosterone: a metabolic hormone in health and disease. J Endocrinol. 2013;217(3):25-45. doi:10.1530/JOE-12-0455

21. Gungor O, Kircelli F, Carrero JJ, et al. Endogenous testosterone and mortality in male hemodialysis patients: is it the result of aging? Clin J Am Soc Nephrol. 2010;5(11):2018-2023. doi:10.2215/CJN.03600410

22. Fouque D, Kalantar-Zadeh K, Kopple J, et al. A proposed nomenclature and diagnostic criteria for protein-energy wasting in acute and chronic kidney disease. Kidney Int. 2008;73(4):391-398. doi:10.1038/ sj.ki.5002585

23. Carrero JJ, Qureshi AR, Nakashima A, et al. Prevalence and clinical implications of testosterone deficiency in men with end-stage renal disease. Nephrol Dial Transplant. 2011;26(1):184-190. doi:10.1093/ ndt/gfq397

24. Chiang JM, Kaysen GA, Segal M, Chertow GM, Delgado C, Johansen KL. Low testosterone is associated with frailty, muscle wasting and physical dysfunction among men receiving hemodialysis: a longitudinal analysis. Nephrol Dial Transplant. 2019;34(5):802810. doi: $10.1093 / \mathrm{ndt} / \mathrm{gfy} 252$

25. Harada K, Suzuki S, Ishii H, et al. Impact of skeletal muscle mass on long-term adverse cardiovascular outcomes in patients with chronic kidney disease. Am J Cardiol. 2017;119(8):1275-1280. doi:10.1016/j. amjcard.2017.01.003

26. Zhou Y, Hellberg M, Svensson P, Höglund P, Clyne N. Sarcopenia and relationships between muscle mass, measured glomerular filtration rate and physical function in patients with chronic kidney disease stages 3-5. Nephrol Dial Transplant. 2018;33(2):342-348. doi:10.1093/ndt/gfw466
27. Watanabe H, Enoki Y, Maruyama T. Sarcopenia in chronic kidney disease: factors, mechanisms, and therapeutic interventions. Biol Pharm Bull. 2019;42(9):1437-1445. doi:10.1248/bpb.b19-00513

28. Cigarrán S, Pousa M, Castro MJ, et al. Endogenous testosterone, muscle strength, and fat-free mass in men with chronic kidney disease. J Ren Nutr. 2013;23(5):89-95. doi:10.1053/j.jrn.2012.08.007

29. Rymarz A, Matyjek A, Gomółka M, Niemczyk S. Lean tissue index and body cell mass can be predictors of low free testosterone levels in men on hemodialysis. J Ren Nutr. 2019;29(6):529-535. doi:10.1053/j. jrn.2019.03.078

30. Amiri M, Ramezani Tehrani F, Rahmati M, et al. Low serum testosterone levels and the incidence of chronic kidney disease among male adults: a prospective population-based study. Andrology. 2020;8 (3):575-582. doi:doi:10.1111/andr.12728

31. Mouser JG, Loprinzi PD, Loenneke JP. The association between physiologic testosterone levels, lean mass, and fat mass in a nationally representative sample of men in the United States. Steroids. 2016;115:62-66. doi:1016/j.steroids.2016.08.009

32. Supasyndh O, Satirapoj B, Aramwit P, et al. Effect of oral anabolic steroid on muscle strength and muscle growth in hemodialysis patients. Clin J Am Soc Nephrol. 2013;8(2):271-279. doi:10.2215/ CJN.00380112

\section{Publish your work in this journal}

The International Journal of Nephrology and Renovascular Disease is an international, peer-reviewed open-access journal focusing on the pathophysiology of the kidney and vascular supply. Epidemiology, screening, diagnosis, and treatment interventions are covered as well as basic

Submit your manuscript here: https://www.dovepress.com/international-journal-of-nephrology-and-renovascular-disease-journal science, biochemical and immunological studies. The manuscript management system is completely online and includes a very quick and fair peer-review system, which is all easy to use. Visit http://www.dovepress.com/testimonials.php to read real quotes from published authors. 